\title{
Removal of $\mathrm{Pb}^{2+}$ and $\mathrm{Cd}^{2+}$ Ions, Colour and Turbidity from Water Using Carbon and Ash Derived From Maize Cobs
}

\author{
*Daniel Muvengei, Haron Mbuvi,Margaret Ng'ang'a
}

\begin{abstract}
About 17.2 million Kenyans lack access to clean water due to increased population growth, high rate of industrialisation and poor waste management. The situation may worsen if immediate measures are not taken. Lead and cadmium are the main heavy metals in contaminated water and their harmful effects such as lung cancer, mental retardation and nerve disorder cannot be under estimated. Available methods for removing these metal ions from water such as use of activated carbon are very expensive and unaffordable to low income earners. Maize cobs which have minimal use after maize harvesting can be utilised to reduce environmental pollution. The primary aim of this study was to investigate the ability of maize cobs derived products to adsorb both lead (II) and cadmium (II) ions and remove methylene blue and turbidity from contaminated water. Maize cobs charcoal was prepared by heating dry maize cobs in a furnace in limited air. Activation was done by use of $1 \mathrm{M}$ sulphuric acid and heating the mixture in a closed vessel. Maize cob ash was generated by heating dry maize cobs in a furnace. Ability of these adsorbents to adsorb lead (II) and cadmium (II) ions from the solution was investigated by carrying out batch experiment and varying parameters such as contact time, initial metal ion concentration, adsorbent dose, temperature and shaking speed. The data obtained was fitted in Langmuir and Freundlich models. Activated charcoal gave the best fit in Langmuir for lead ions with maximum adsorption capacity of $13.0 \mathrm{mg} / \mathrm{g}$. Ash fitted in Freundlich model with $r^{2}=0.953$. For removal of cadmium (II) ions, all the adsorbents gave best fit in Freundlich with maize cob charcoal having the highest adsorption capacity of 24.3 $\mathrm{mg} / \mathrm{g}$ and $r^{2}=0.997$. Among the three adsorbent only ash was found to have the ability of removing turbidity from water. This implies that maize cob derived products can be used to remove lead (II) and cadmium (II) ions from waste water.
\end{abstract}

\section{Introduction}

The world population increased threefold in $20^{\text {th }}$ century thus increasing the need of renewable water resources $^{1}$. This population advancement coupled with industrialization and urbanisation has led to greater demand and shortage for water worldwide. According to estimates by WHO/UNICEF in 2000, more than two out of five people lacked access to safe drinking water by $2000^{2}$. In Kenya, 17.2 million People who constitute about 43 percent of the population have no access to clean water. This situation may worsen due to the rapid population growth in both rural and urban areas that stresses the existing water supply systems ${ }^{3}$. Further, this has been accompanied by remarkable growth in light and informal (jua kali) industries like textiles, leather, paper, plastics, electroplating, cement, metal processing, wood preservatives, paints, pigments and steel fabricating industries ${ }^{4}$ which discharge large quantities of toxic wastes ${ }^{5}$. Recent studies on open-air mechanical workshops in Kenya have reported that they contribute significant amounts of mobile and bioavailable heavy metal contaminants ${ }^{6,7}$. There are several ways that dissolved heavy metals can be removed from water that include ion exchange, reverse osmosis, precipitation, ultrafiltration, , electrodialysis and adsorption ${ }^{8}$. Most of them require high energy and advanced operations that are out of reach to many low income earners. Higher turbidity increases water temperatures because suspended particles absorb more heat. This, in turn, reduces the concentration of dissolved oxygen (DO) because warm water holds less DO than cold. Removal of colour is a function of water treatment. Coloured water can limit the penetration of light. Thus highly coloured body water cannot sustain aquatic life which can lead to long term impairment of ecosystem.

Consequently, this study explores possibilities of developing cheap water treatment adsorbent from agricultural waste maize cobs. The elemental composition of maize cob ash was determined to establish the suitability of maize cob products in water remediation. Indeed findings herein suggest that maize cobs can be used as raw materials for developing adsorbent materials for heavy metal removal from contaminated water.

\section{Methods And Materials}

Preparation of activated charcoal and ash

Maize cobs used in this study were collected from a local farmer in Ruiru district in Kiambu County. The cobs were transported to the laboratory where they were washed with distilled water and sun dried. The dry maize cobs were heated in furnace in absence of air by use of tightly closed clay pots at a temperature of $400^{\circ} \mathrm{C}$ for eight hours. The charcoal obtained was cooled in air and crushed to finer particles using motor and pestle. Activation was done by mixing charcoal powder from the cobs and $1 \mathrm{M}$ sulphuric acid in the ratio of $1: 2$ 
respectively ( density of the acid $1.98 \mathrm{~g} / \mathrm{cm}^{3}$ ) followed by heating in absence of air in the furnace at a temperature of $350{ }^{\circ} \mathrm{C}$ for six hours. Ash from maize cobs was made by heating dry maize cobs in a furnace at a temperature of $400{ }^{\circ} \mathrm{C}$ in presence of air. The chemical composition of the ash obtained was determined by $\mathrm{X}$ ray diffraction method. The adsorption studies for lead and cadmium were done using non-activated charcoal, activated charcoal and ash.

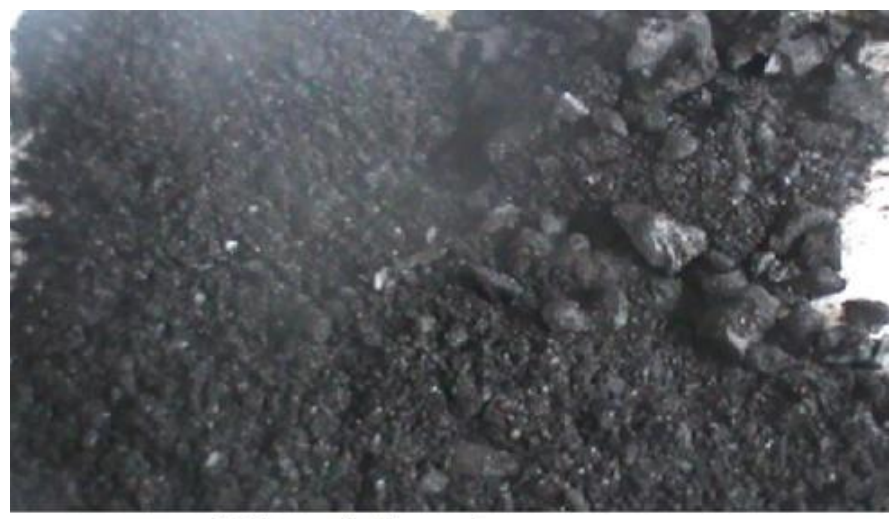

Maize cob charcoal

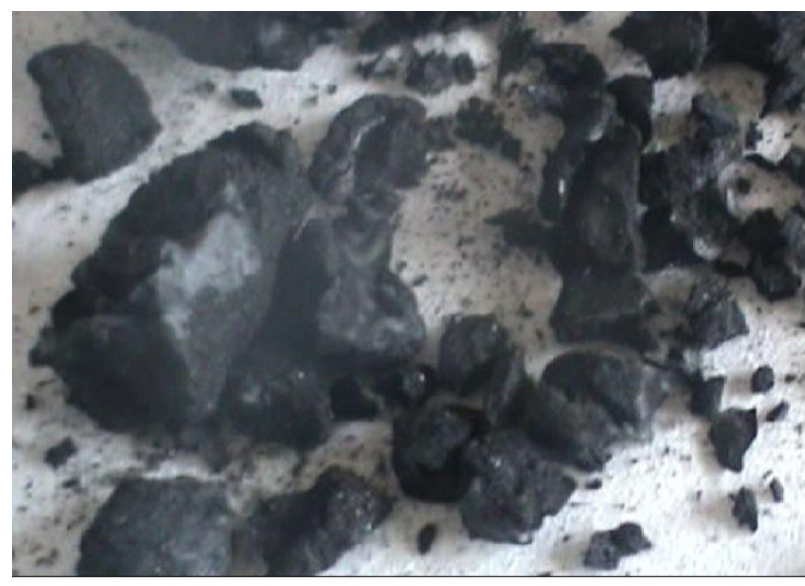

Activated maizecob Charcoa

\section{Preparation of standard and test solution of $\mathrm{Pb}^{2+}$ and $\mathrm{Cd}^{2+}$ ions}

$1.5990 \mathrm{~g}$ of analytical grade lead nitrates was dissolved in $200 \mathrm{~mL}$ of distilled water. The resulting solution was diluted to $1000 \mathrm{~mL}$ mark using distilled water. This was the $1000 \mathrm{ppm}$ stock solutions of lead. Standard solutions of $2,4,6,8$ and10 ppm were prepared by successive dilution of the stock solution. Cadmium nitrate was prepared in the same way by measuring $2.745 \mathrm{~g}$ of cadmium nitrate.

\section{Instrumentation}

$\mathrm{The}^{\mathrm{Pb}^{2+}}$ and $\mathrm{Cd}^{2+}$ ion concentrations in the various solutions were determined using atomic absorption spectrophotometer model AAS 4141, ECIL, India at wavelength $283.3 \mathrm{~nm}$ for lead and $228.9 \mathrm{~nm}$ for cadmium in flame mode using air-acetylene flame. The pH meter, model PHEP, Hanna instrument, Italy, was used in this study at a $\mathrm{pH}$ of 7 which was adjusted using a buffer of 7 and a temperature of $22.7^{\circ} \mathrm{C}$. All concentrations were determined in triplicates. A standard and blank sample was run after every seven samples to check instrumental drift. Calibration curve method was used to quantify the heavy metal concentration. Turbidity of water was determined using Turbidimeter, model $2100 \mathrm{P}(\mathrm{HACH})$ while colour was determined by U.V spectrophotometer, model C $\equiv 2041,2000$ series at wavelength $601.0 \mathrm{~nm}$.

\section{Batch experiments}

A temperature-controlled water-bath shaker (DKZ-1 NO.1007827) was used for the batch adsorption experiments. The experiments were performed at the same shaking speed. For each experimental run, $50 \mathrm{~mL}$ aqueous solution of known concentrations of $\mathrm{Pb}^{2+}$ and $\mathrm{Cd}^{2+}$ ionswere put in $120 \mathrm{~mL}$ plastic bottles that contained known masses of maize cob charcoal(MC),activated maize cob charcoal(AMC) and Ash. These bottles were agitated at a constant shaking rate of $360 \mathrm{rpm}$ and temperature of $25^{\circ} \mathrm{C}$ for 120 minutes, centrifuged and filtered. The concentration of $\mathrm{Pb}^{2+}$ and $\mathrm{Cd}^{2+}$ ions in the filtrates obtained were measured using flame atomic adsorption 
spectrometry. The amount of $\mathrm{Cd}^{2+}$ and $\mathrm{Pb}^{2+}$ ions adsorbed per unit mass of adsorbent and the percentage of $\mathrm{Pb}^{2+}$ and $\mathrm{Cd}^{2+}$ ions removed were calculated using equations 1 and 2 respectively

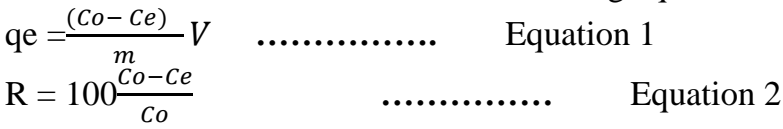

Where,

$\mathrm{qe}=$ Amount of $\mathrm{Pb}^{2+}$ or $\mathrm{Cd}^{2+}$ ions adsorbed per unit mass of adsorbent at equilibrium.

$\mathrm{Co}=$ Initial concentration of sorbate.

$\mathrm{Ce}=$ Concentration of sorbate at equilibrium.

$\mathrm{m}=$ mass of sorbate (atomic mass).

$\mathrm{V}=$ volume of solution,

$\mathrm{R}=$ percentage removal

\section{Effect of the various parameters on the percentage of $\mathrm{Pb}^{2+}$ and $\mathrm{Cd}^{2+}$ ions adsorbed}

The effects of various parameters (adsorbent dose, contact time, initial concentrations, $\mathrm{pH}$ and temperature) on the percentage of $\mathrm{Pb}^{2+}$ and $\mathrm{Cd}^{2+}$ ions adsorbed were investigated by varying one parameter while keeping all the others constant. For $\mathrm{Pb}^{2+}$ and $\mathrm{Cd}^{2+}$, the effect of initial concentrations were investigated by varying initial concentration from 5 to $25 \mathrm{ppm}$ i.e. $5,10,15 \mathrm{ppm}, 20$ and 25 at same conditions of: $0.2 \mathrm{~g}$ adsorbent, $25^{\circ} \mathrm{C}, 2 \mathrm{Hrs}, 240 \mathrm{rpm}$ and $\mathrm{PH} 7$. The effect of the adsorbent dosage was investigated at varying doses of $0.1,0.2,0.3,0.4$ and $0.5 \mathrm{~g}$ at same conditions of: $10 \mathrm{ppm}, 25^{\circ} \mathrm{C}, 2 \mathrm{Hrs}, 240 \mathrm{rpm}$ and $\mathrm{PH} 7$.. The effect of contact time was investigated by varying contact time from 1 to $14400 \mathrm{~min}$ at same conditions of: $10 \mathrm{ppm}, 0.2 \mathrm{~g}$ adsorbent, $25^{\circ} \mathrm{C}, 240 \mathrm{rpm}$ and $\mathrm{PH} 7$.. The effect of shaking speed was investigated by varying agitation speed from 0 to $360 \mathrm{rpm}$ at same conditions of $0.2 \mathrm{~g}$ adsorbent, $25^{\circ} \mathrm{C}, 10 \mathrm{ppm}, 2 \mathrm{Hrs}$ and $\mathrm{PH} 7$.

\section{Removal of colour}

To investigate removal of colour by the three adsorbents, methylene blue was used to add colour in water. $1 \mathrm{~g}$ of methylene blue was dissolved in one litre of distilled water to make $1000 \mathrm{ppm}$ of solution from which working solutions of 5, 10, 15, 20 and $25 \mathrm{ppm}$ were prepared by dilution. To $100 \mathrm{~mL}$ of the solution $0.2 \mathrm{~g}$ of the adsorbent was added. The mixture was shaken for two hours at constant shaking speed after which it was centrifuged and filtered. The intensity of methylene blue colour remaining in solution was measured using UV visible spectroscopy.

\section{Removal of turbidity}

To investigate turbidity removal from water, $20 \mathrm{~g}$ of red soil was added to $1000 \mathrm{~mL}$ of distilled water, stirred for about 10 minutes and allowed to settle. The mixture was then filtered and turbidity of the water measured using turbidity meter. Five water samples of $100 \mathrm{~mL}$ each were put in different bottles. Different adsorbent dose of $0.1,0.2,0.3,0.4$ and $0.5 \mathrm{~g}$ were added to water samples which were then shaken at constant speed for two hours. The mixture was filtered and turbidity of filtrate measured. This was done for all the three adsorbents.

Elemental Composition of Ash

\section{Results And Discussion}

The percentage composition of major elements in maize cob ash was analysed by use of X-ray fluorescence (XRF). Table 1 shows percentage composition of elements present.

Table 1: Elemental composition of ash

\begin{tabular}{|l|l|l|l|l|l|l|l|l|l|l|l|}
\hline oxide & $\mathrm{SiO}_{2}$ & $\mathrm{P}_{2} \mathrm{O}_{5}$ & $\mathrm{SO}_{3}$ & $\mathrm{Cl}$ & $\mathrm{K}_{2} \mathrm{O}$ & $\mathrm{CaO}$ & $\mathrm{TiO}_{2}$ & $\mathrm{MnO}$ & $\mathrm{Fe}_{2} \mathrm{O}_{3}$ & $\mathrm{ZnO}$ & $\mathrm{PbO}$ \\
\hline$\%$ & 15 & 2.3 & 4.8 & 6.1 & 67.1 & 3.1 & 0.07 & 0.1 & 1.0 & 0.49 & 0.08 \\
\hline
\end{tabular}

Table 1 shows different oxide present in maize cob ash. As shown, the major elements (oxides) found in maize cob ash were $\mathrm{K}_{2} \mathrm{O}, \mathrm{SiO}_{2}, \mathrm{Cl}, \mathrm{SO}_{3}, \mathrm{CaO}, \mathrm{P}_{2} \mathrm{O}_{5}$ and $\mathrm{Fe}_{2} \mathrm{O}_{3}$ at percentages of $67.1,15,6.1,4.8,3.1,2.3$ and 1.0 respectively. $\mathrm{ZnO}$ and $\mathrm{MnO}$ were found in small amounts of 0.49 and 0.1 respectively while $\mathrm{PbO}_{\text {and }} \mathrm{TiO}_{2}$ were detected at even smaller percentages of 0.08 and 0.07 respectively. This indicates that no toxic elements other than $\mathrm{PbO}$ are present in the ash. The low level of $\mathrm{PbO}$ at $0.08 \%$ coupled with its insolubility in water shows that the ash is safe for use in water treatment.

Batch adsorption experiments Effect of initial metal ion concentration 
The percentages of $\mathrm{Pb}^{2+}$ ions adsorbed by ash, charcoal and activated charcoal from maize cobs were significantly influenced by the initial concentrations of $\mathrm{Pb}^{2+}$ ions in aqueous solutions. The initial concentrations of $\mathrm{Pb}^{2+}$ were varied from 5 to $200 \mathrm{mg} / \mathrm{L}$ while maintaining the adsorbent dosage at $0.2 \mathrm{~g}$. Figure 1 shows the effect of initial concentration on percentage removal of $\mathrm{Pb}^{2+}$ ions. The percentage removal of $\mathrm{Pb}^{2+}$ decreased from $100 \%$ for $5 \mathrm{ppm}$ to $68 \%$ for $200 \mathrm{mg} / \mathrm{L}$ at a contact time of $2 \mathrm{hrs}$ and adsorption temperature of $25^{\circ} \mathrm{C}$ when $0.2 \mathrm{~g}$ of maize cobs charcoal, (MC) was used. Decrease in percentage removal using MC adsorbent suggested that amount of $\mathrm{Pb}^{2+}$ ions surpassed the fixed number of available active sites. The trend was different for activated maize cobs charcoal (AMC) and Ash since the percentage removal increased with increase in concentration then a decrease. At $5 \mathrm{mg} / \mathrm{L}$ the percentage removal was 40 percent which increased to $98 \%$ at 25 $\mathrm{mg} / \mathrm{L}$ the percentage removal then decreased up to $20 \%$ at $200 \mathrm{mg} / \mathrm{L}$. This could have been caused by saturation of the pores at low (high) concentrations. The percentage removal by ash increased from $16 \%$ at 5 ppm to $65 \%$ at $20 \mathrm{ppm}$ then decreased to $30 \%$ at $200 \mathrm{ppm}$. Saturation of the adsorbent pores could have led to decrease in percentage removal.

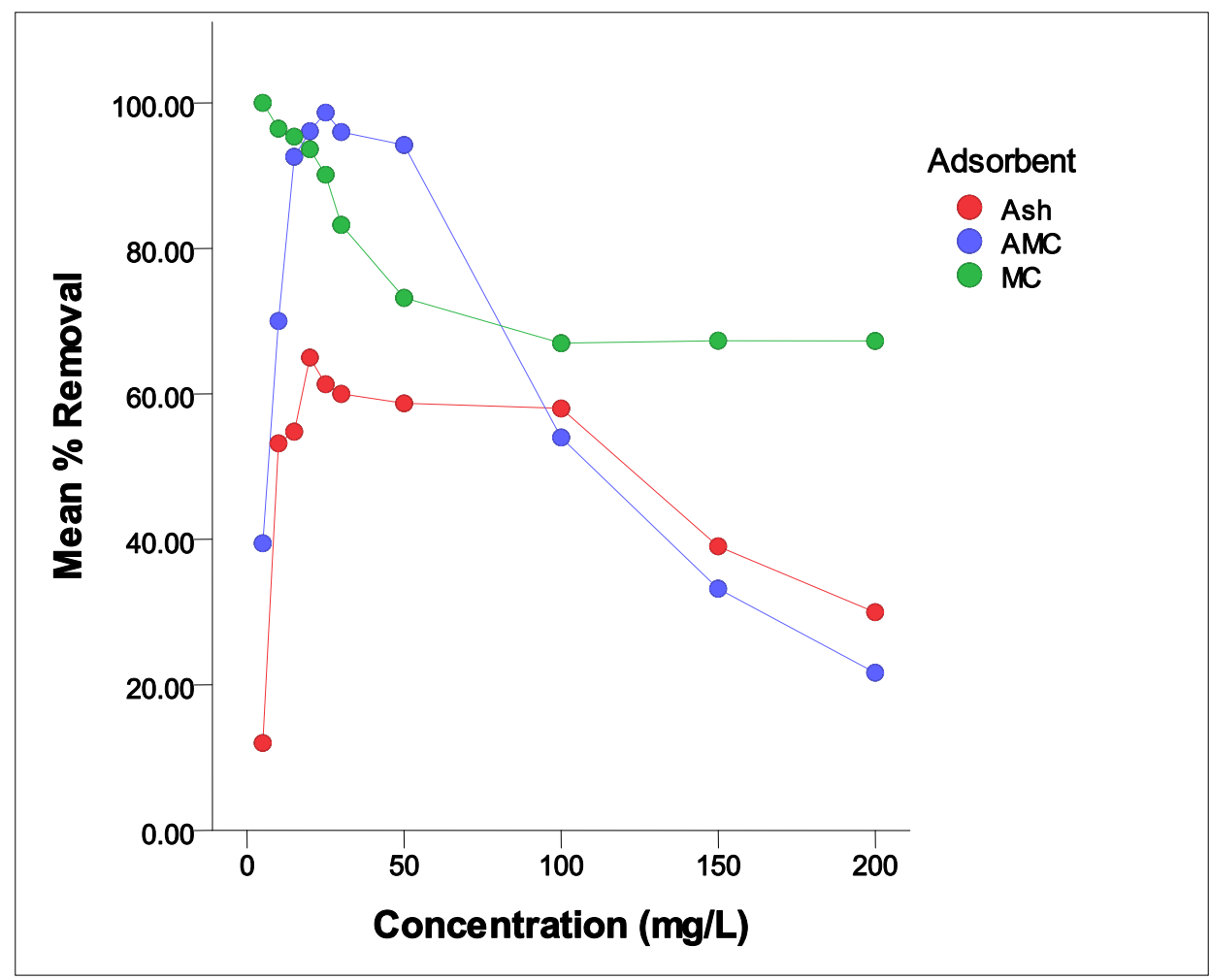

Fig 1: Effect of initial metal concentration on percentage removal of lead (II) ions $\left(0.2 \mathrm{~g}, 25^{\circ} \mathrm{C}, 2 \mathrm{Hrs}, 240 \mathrm{rpm}\right.$ and $\mathrm{PH} 7$ )

The effects of percentage removal of $\mathrm{Cd}^{2+}$ ions at various initial concentrations are presented in figure 2. Both AMC and Ash adsorbents showed a similar trend, a general increase in percentage removal as initial concentrations were increased, MC showed percentage removal decrease as the initial concentration was increased. The percentage removal efficiencies of ash and activated maize cobs increased from 5 to $92 \%$, and 22 to $92 \%$ respectively as initial concentration was varied from 5 to $200 \mathrm{ppm}$ for maize cob charcoal the percentage removal decreased from 100 to $78 \%$. The percentage removal beyond initial concentration of 20 $\mathrm{mg} / \mathrm{l}$ for MC adsorbents started to decrease, suggesting saturation of the finite active sites on adsorbent surface with the metal ions. 


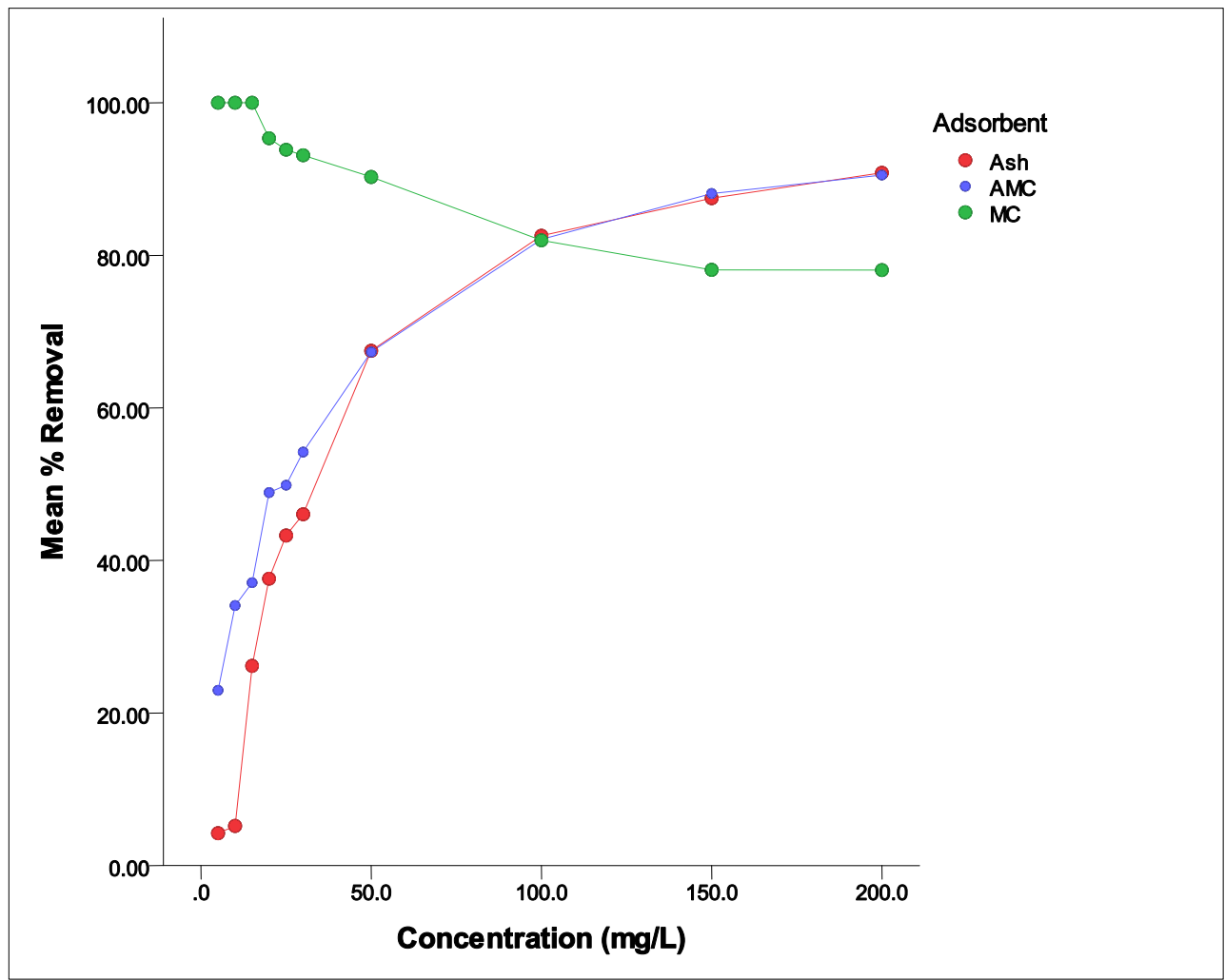

Fig 2: Effect of initial metal ion concentration on percentage removal of cadmium (II) ions $\left(0.2 \mathrm{~g}, 25^{\circ} \mathrm{C}, 2 \mathrm{Hrs}\right.$, 240rpm and $\mathrm{PH} 7$ )

\section{Effect of contact time}

Experiments were conducted by, varying contact time from 1 to 1440 min while maintaining all other experimental conditions same $\left(0.2 \mathrm{~g}\right.$ of the adsorbent, $10 \mathrm{ppm}$ of $\mathrm{Pb}^{2+}$ and $\mathrm{Cd}^{2+}$, temperature of $25^{\circ} \mathrm{C}$, shaking speed $240 \mathrm{rpm}$ and $\mathrm{pH} 7$ ). The results obtained are shown in table 2. As shown the three adsorbents gave the similar trend. The percentage removal of $\mathrm{Pb}^{2+}$ ions increased as contact time was increased until a plateau was reached at $150 \mathrm{~min}$ for all adsorbents. One sample in each case was shaken upto $1440 \mathrm{~min}$ in order to get maximum adsorption capacity for the adsorbents Activated maize cob charcoal gave the highest percentage removal after 150 min compared to the other adsorbents. The percentage removal efficiency for AMC at equilibrium time (150 min) was $79.89 \%$ while that of ash was $77 \%$ and $\mathrm{MC}$ was $68 \%$ at the same shaking speed and constant adsorbent dose of $0.2 \mathrm{~g}$. At the equilibrium time for both adsorbents no more adsorption could take place due to rates of adsorption being equal to the rate of desorption.

Table 2: Effect of contact time on the percentage removal of lead (II) ions $\left(0.2 \mathrm{~g}, 25^{\circ} \mathrm{C}, 10 \mathrm{ppm}, 240 \mathrm{rpm}\right.$ and $\mathrm{pH} 7$ )

\begin{tabular}{|l|r|r|r|}
\hline Adsorbent & AMC & MC & \multicolumn{1}{c|}{$\begin{array}{c}\text { Mean } \\
\text { \% removal } \pm \text { SE }\end{array}$} \\
\hline Time(mins) & $\begin{array}{c}\text { Mean } \\
\text { \% removal } \pm \text { SE }\end{array}$ & $\begin{array}{c}\text { Mean } \\
\text { \% remova SE }\end{array}$ & $67.26 \pm 0.67$ \\
\hline 30 & $55.95 \pm 0.01$ & $43.20 \pm 0.00$ & $71.06 \pm 1.33$ \\
\hline 60 & $70.83 \pm 0.06$ & $62.60 \pm 0.00$ & $73.21 \pm 1.33$ \\
\hline 90 & $75.61 \pm 0.00$ & $69.09 \pm 0.02$ & $75.95 \pm 0.33$ \\
\hline 120 & $78.07 \pm 0.00$ & $72.31 \pm 0.00$ & $77.60 \pm 0.67$ \\
\hline 150 & $79.52 \pm 0.01$ & $74.24 \pm 0.07$ & $77.91 \pm 1.20$ \\
\hline 1440 & $79.71 \pm 0.11$ & $74.36 \pm 0.04$ & \\
\hline
\end{tabular}

The variation of contact time on percentage of adsorbed cadmium (II) ions showed a similar trend for the three adsorbents as shown in table 3. The percentage removal increased with increase in contact time.. Ash gave the highest percentage removal for cadmium ions at the equilibrium time ( 86 percent) followed by AMC which gave a percentage of 69 and $\mathrm{MC}$ gave $60 \%$. The trend observed for both cadmium and lead is in agreement with findings of Ho and Mckay (1998) ${ }^{9}$. The nature of the adsorbent and its available sorption sites affected the time needed to reach equilibrium. This may be explained by the fact that initially a large number of vacant sites were available and as the adsorption process continued, much of the available sites were used up 
Removal Of $\mathrm{Pb}^{2+}$ And $\mathrm{Cd}^{2+}$ Ions, Colour And Turbidity From Water Using Carbon And Ash Derived ..

which slowed the process down later due to exhaustion of remaining surface sites and repulsive forces developed between solute molecules and bulk phase ${ }^{10}$.

Table 3: Effect of contact time on percentage removal of cadmium (II) ions $\left(0.2 \mathrm{~g}, 25^{\circ} \mathrm{C}, 10 \mathrm{ppm}, 240 \mathrm{rpm}\right.$ and

\begin{tabular}{|c|c|c|c|}
\hline \multicolumn{4}{|c|}{$\mathrm{pH}=7)$} \\
\hline Adsorbents & AMC & $\mathrm{MC}$ & $\mathrm{ASH}$ \\
\hline Time(mins) & $\begin{array}{r}\text { Mean } \\
\% \text { removal } \pm \mathrm{SE} \\
\end{array}$ & $\begin{array}{r}\text { Mean } \\
\% \text { removal } \pm \text { SE }\end{array}$ & $\begin{array}{r}\text { Mean } \\
\% \text { removal } \pm \text { SE }\end{array}$ \\
\hline 30 & $58.68 \pm 1.66$ & $60.01 \pm 0.22$ & $84.31 \pm 0.53$ \\
\hline 60 & $63.07 \pm 1.78$ & $60.54 \pm 0.23$ & $86.25 \pm 0.54$ \\
\hline 90 & $64.30 \pm 1.82$ & $60.68 \pm 0.21$ & $86.91 \pm 0.55$ \\
\hline 120 & $66.34 \pm 1.88$ & $60.93 \pm 0.23$ & $87.24 \pm 0.55$ \\
\hline 150 & $70.43 \pm 1.99$ & $61.41 \pm 0.22$ & $87.44 \pm 0.55$ \\
\hline 1440 & $70.42 \pm 1.99$ & $61.52 \pm 0.23$ & $88.15 \pm 0.55$ \\
\hline
\end{tabular}

Effect of dosage on percentage removal of metal ions

Batch experiments were conducted with the adsorbent dose of $0.1,0.2,0.3,0.4$ and $0.5 \mathrm{~g}$ per 50

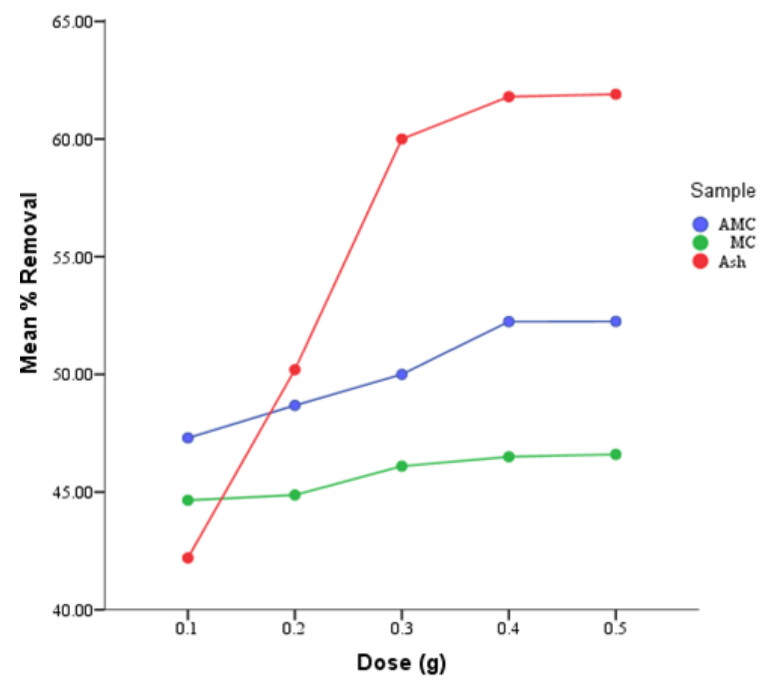

Figure 3: Effect of adsorbent dose on percentage removal of lead (II) ions $\left(25^{\circ} \mathrm{C}, 10 \mathrm{mg} / \mathrm{L}, 2 \mathrm{Hrs}, 240 \mathrm{rpm}\right.$ and $\mathrm{pH} 7)$

$\mathrm{mL}$ of test solution $(10 \mathrm{mg} / \mathrm{L})$. When the adsorbent dose increased, the percentage removal of metal ions also increased as shown in Fig 3. Adsorption of lead ions increased due to increase in number of binding sites as the adsorbent dose increased. Ash recorded the highest percentage removal of about $62 \%$ at a dose of $0.4 \mathrm{~g}$ followed by AMC which gave $52 \%$ at a dose of $0.4 \mathrm{~g}$ while MC gave its highest percentage of $46 \%$ at a dose of $0.3 \mathrm{~g}$.

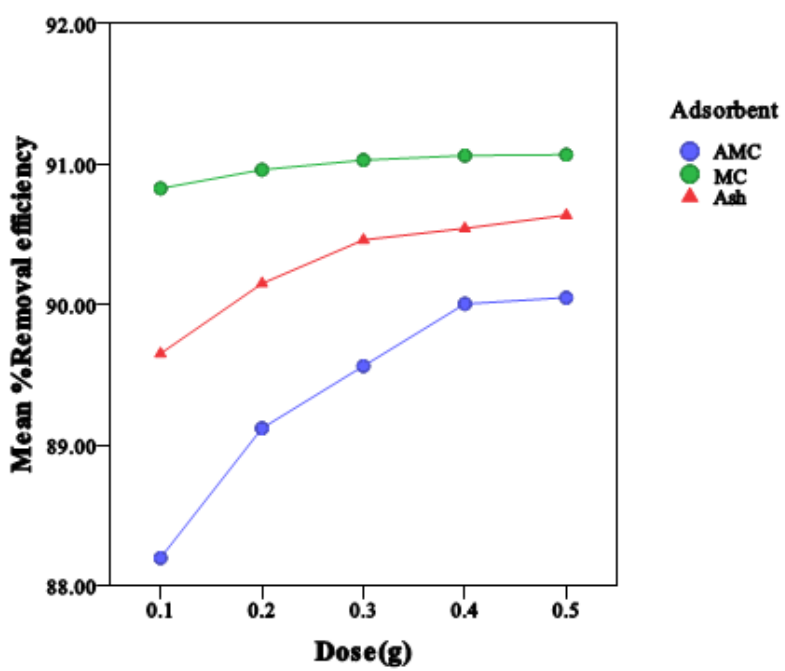


Fig 4: Effect of adsorbent dose on percentage removal of cadmium (II) ions $\left(25^{\circ} \mathrm{C}, 10 \mathrm{ppm}, 2 \mathrm{Hrs}, 240 \mathrm{rpm}\right.$ and $\mathrm{pH} 7$ )

Figure 4 shows variations in the percentage removal of cadmium (II) ions as the adsorbent doses were increased. The highest percentage removal by maize cob charcoal (MC) was $91 \%$ at a dose of $0.3 \mathrm{~g}$ followed by ash which gave $90.5 \%$ at a dose of $0.5 \mathrm{~g}$ while activated maize cob charcoal (AMC) gave $90 \%$ at $0.4 \mathrm{~g}$. MC plateaued at $0.3 \mathrm{~g}$ and $\mathrm{AMC}$ at $0.4 \mathrm{~g}$. Increase in percentage removal is due to increase in adsorbent surface area as well as the active sites available as the adsorbent is increased. No increase in percentage removal beyond $0.4 \mathrm{~g}$ of adsorbent. This is associated to saturation of adsorption sites as reported by Mureithi et al., 2012 using water hyacinth as the adsorbent ${ }^{11}$.

\section{Effect of shaking speed}

The effect of shaking speed on percentage removal of lead (II) ion was investigated for two adsorbents using $50 \mathrm{~mL}$ of solution whose metal ion concentration was $10 \mathrm{mg} / \mathrm{l}$. The results in fig 5 show that as the shaking speed is increased the percentage removal of the metal ion also increased.

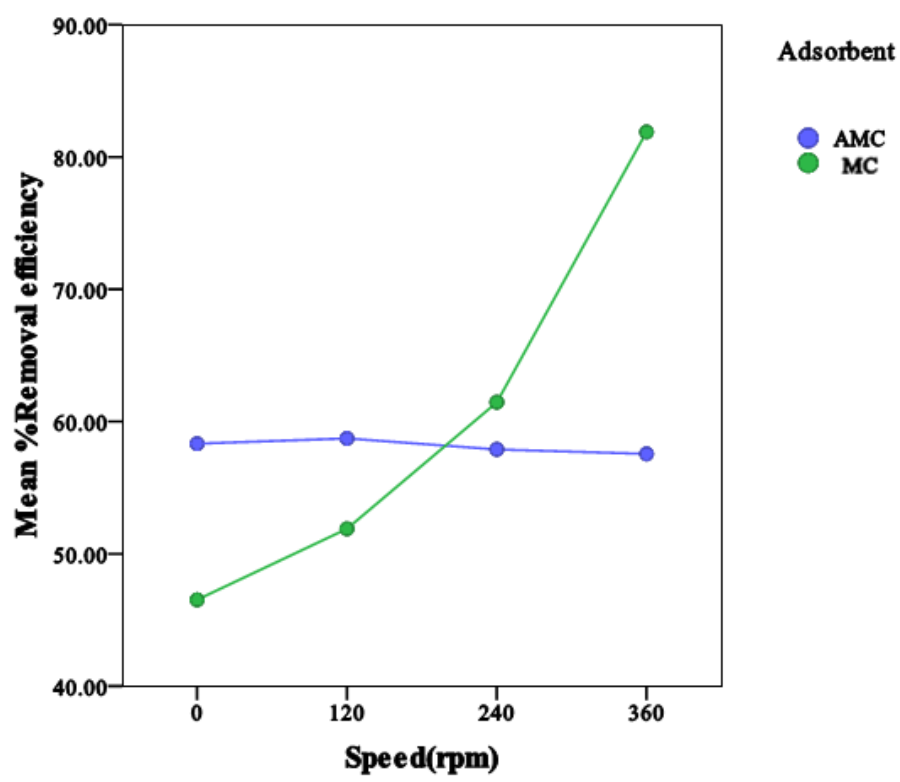

Fig 5: Effect of shaking speed on percentage removal of lead (II) ions $\left(0.2 \mathrm{~g}, 25^{\circ} \mathrm{C}, 10 \mathrm{ppm}, 2 \mathrm{Hrs}\right.$ and $\left.\mathrm{pH}=7\right)$

The maximum percentage removal for AMC was $60 \%$ at $120 \mathrm{rpm}$ and for MC was $81 \%$ at $360 \mathrm{rpm}$. For cadmium (II) ions, percentage removal increased with increase in shaking speed, for AMC the percentage removal increased from 51 to $80 \%$ at 240rpm and for MC the percentage removal increased from 65 to $77 \%$ at $240 \mathrm{rpm}$ as shown in figure 6 . For both adsorbents the maximum percentage removal was attained at a shaking speed of 240 revolutions per minute. 

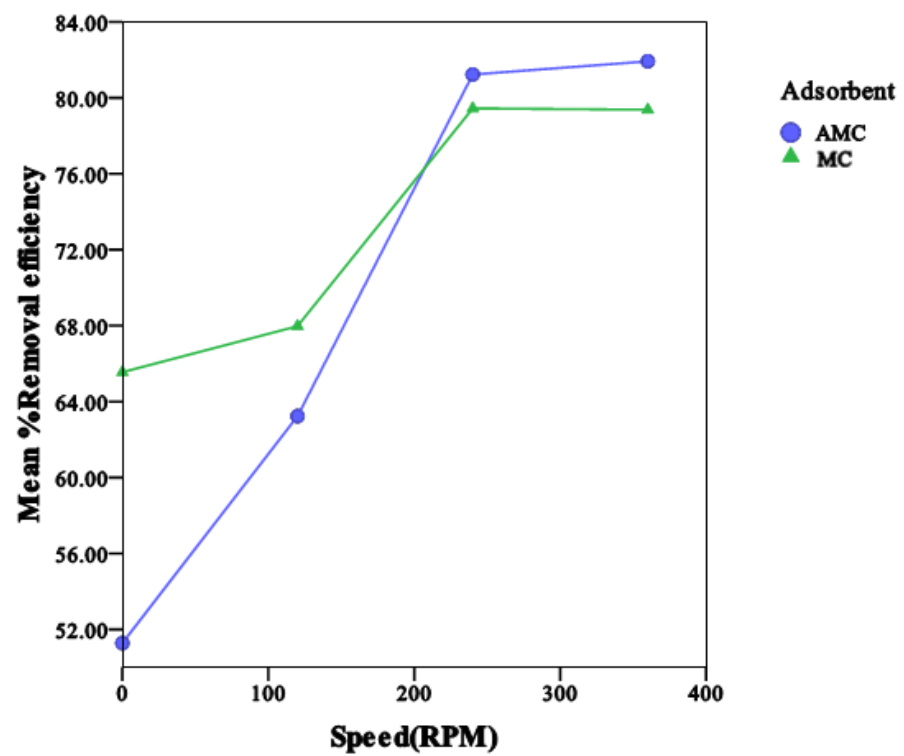

Fig 6: Effect of shaking speed on percentage removal of cadmium (II) ions $\left(0.2 \mathrm{~g}, 25^{\circ} \mathrm{C}, 10 \mathrm{mg} / 1,2 \mathrm{Hrs}\right.$ and $\left.\mathrm{pH} 7\right)$

This is due to increased diffusion rate of metal ions from the bulk liquid to the liquid boundary layer surrounding sorbent particles as the agitation speed is increased ${ }^{12}$. Enhancement of turbulence also ensures good diffusion of ions towards the sorbent particles. Low et al. [1997] suggested that increasing the agitation rate increases the external film mass transfer coefficient hence the rate of uptake due to reduction of the film boundary layer surrounding the sorbent particles ${ }^{13}$.

\section{Effect of temperature}

The effect of temperature on the percentage removal of lead (II) ions is shown in figure 7. From the figure it is clear that the percentage removal efficiency decreased with increase in temperature for both activated maize cob charcoal and Ash. The maximum percentage removal occurred at low temperatures.

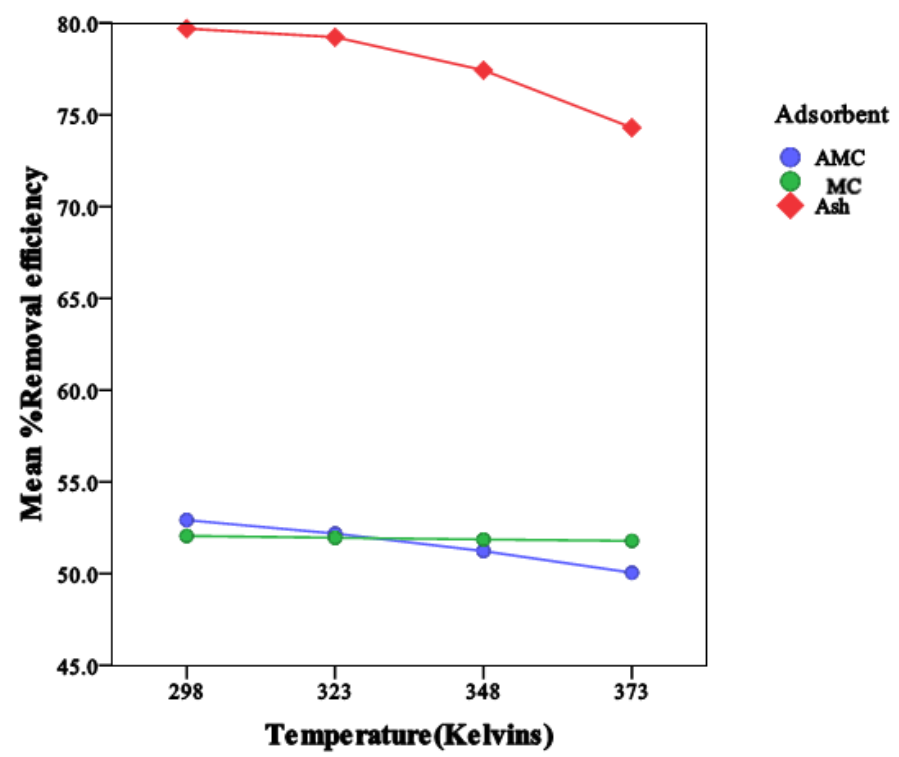

Fig 7: effect of temperature on percentage removal of lead (II) ions(0.2g, 10ppm, 2Hrs 240rpm and pH7)

Ash recorded the highest percentage removal for lead (II) ions of $79 \%$ at $25^{\circ} \mathrm{C}$ which decreased to $74 \%$ at $100^{\circ} \mathrm{C}$ followed by activated maize cob charcoal (AMC) which showed a decrease from $53 \%$ at $25^{\circ} \mathrm{C}$ to $49 \%$ at $100^{\circ} \mathrm{C}$ while for maize cob charcoal ( MC) the percentage removal was almost constant at all temperatures. Increasing the temperature increases the kinetic energy of metal ions which overcomes the binding energy making the particles not to bind on the surface of the adsorbent. 

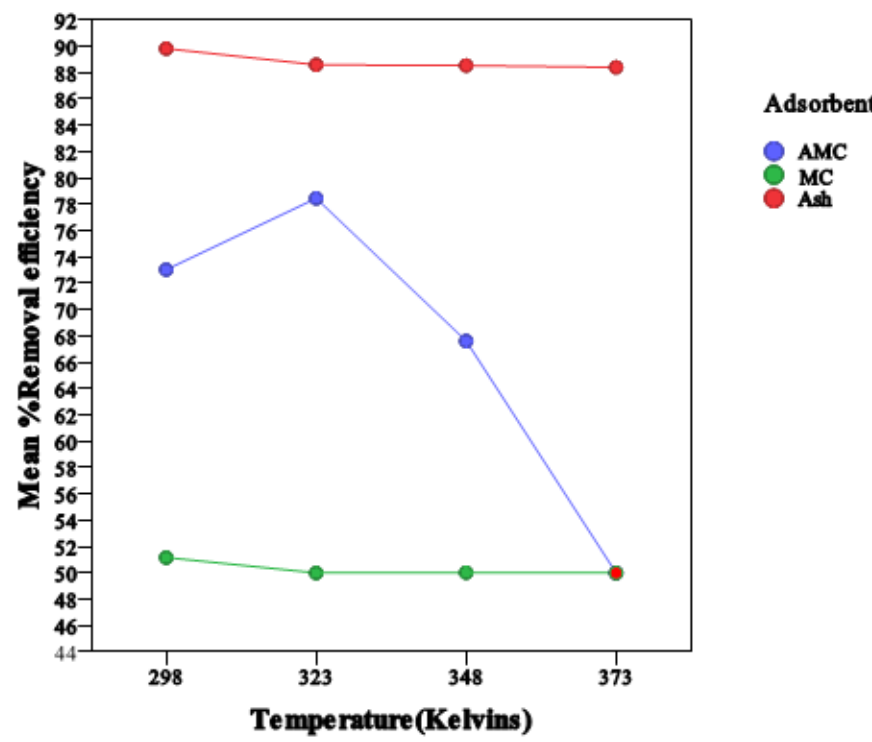

Fig 8: Effect of temperature on percentage removal of cadmium (II) ions $(0.2 \mathrm{~g}, 10 \mathrm{ppm}, 2 \mathrm{Hrs}, 240 \mathrm{rpm}$ and $\mathrm{PH}=7$ )

Same trend was observed for adsorption of cadmium (II) ions on ash and MC, the percentage removal decreased with increase in temperature with the highest percentage removal been recorded at low temperatures. Ash recorded the highest percentage removal of $90 \%$ at $25^{\circ} \mathrm{C}$ which decreased to $87 \%$ at $100^{\circ} \mathrm{C}$, the percentage removal for AMC increased from $72 \%$ at $25^{\circ} \mathrm{C}$ to $78 \%$ at $50^{\circ} \mathrm{C}$ then decreased to $52 \%$ at $100^{\circ} \mathrm{C}$ this suggest that maximum adsorption occurred at $323 \mathrm{k}$. For MC the percentage removal was almost constant for all temperatures. Adsorption of metal ions is an exothermic reaction hence it is favoured at low temperature ${ }^{14}$. The trend can also be explained by the fact that, increasing the temperature increases the kinetic energy of metal ions which in turn overcomes the binding energy making the metal ions not to bind to the surface.

\section{Removal of methylene blue}

Figure 9 shows the effect of concentration on percentage removal of methylene blue from water. The percentage removal increases with increase in concentration for ash and maize cob charcoal. For activated charcoal, percentage removal increased as the initial concentration was increased then followed by a slight decrease. Increased concentration led to increased binding sites hence high percentage removal. Among the three adsorbents, MC gave the highest percentage removal of methylene blue of $86 \%$ from water at $25 \mathrm{mg} / \mathrm{L}$. Similar results were previously reported by Alzaydien, 2009 who investigated adsorption of methylene blue from aqueous onto a low cost natural Joranian Tripoli ${ }^{15}$.

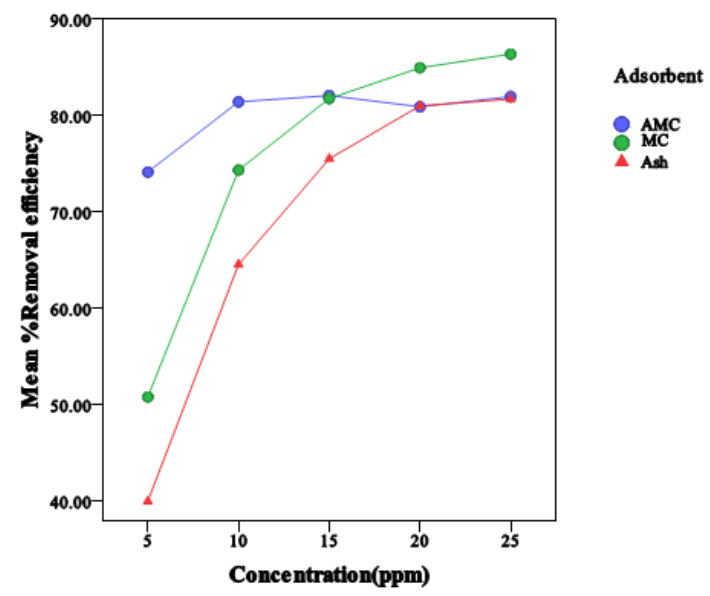

Fig 9: Effect of concentration on percentage removal of colour $\left(0.2 \mathrm{~g}, 25^{\circ} \mathrm{C}, 2 \mathrm{Hrs}, 240 \mathrm{rpm}\right.$ and $\left.\mathrm{pH}=7\right)$

\section{Removal of suspended particles}


Figure 10 shows the effect of adsorbent dose on removal of turbidity from water using ash. The graph shows that the percentage removal of turbidity from water increases with increase in adsorbent dose because as the adsorbent dose is increased more surface is available for adsorption. After a dosage of $0.2 \mathrm{~g}$ the percentage removal was almost constant. The highest percentage removal was $60 \%$ at dosage of $0.5 \mathrm{~g}$. AMC and MC were found to increase turbidity rather than reducing it.

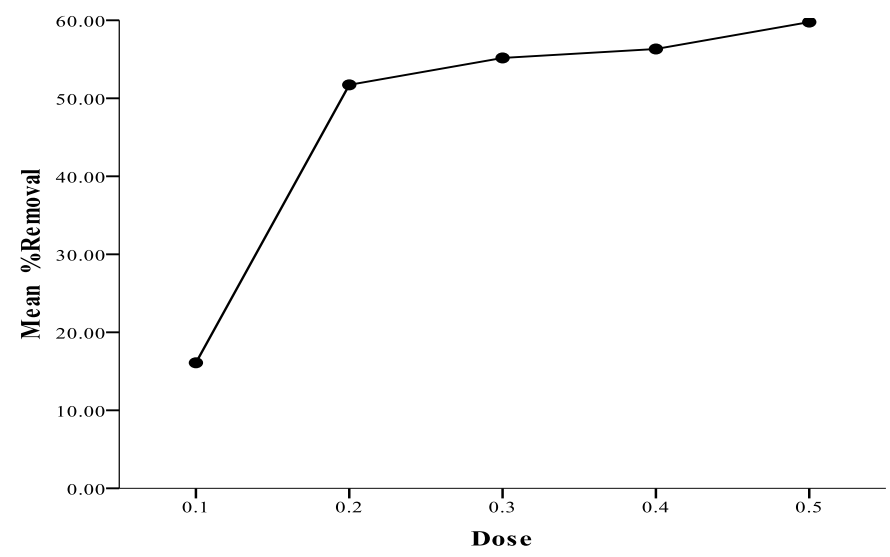

Fig 10: Effect of adsorbent dose on turbidity removal using ash from maize cobs $\left(25^{\circ} \mathrm{C}, 10 \mathrm{ppm}, 2 \mathrm{Hrs}, 240 \mathrm{rpm}\right.$ and $\mathrm{pH}=7$ )

Adsorption isotherms for lead and cadmium (II) ions and methylene blue

The data obtained for both lead (II) and cadmium (II) ions was fitted into linearized equations of Langmuir and Freundlich models. The thermodynamic constants obtained for maize cob charcoal, activated maize cob charcoal and ash are summarized in Table 3-5. The results obtained for lead using the three adsorbents were fitted in both Langmuir and Freundlich isotherm and the constants obtained for both models are shown in Table 3. As shown on activated maize cob charcoal and maize cob charcoal best fitted into the Langmuir model based on $\mathrm{R}^{2}$ values of 0.934 and 0.925 respectively. The adsorption capacities, $\mathrm{q}_{\max }$, of AMC and MC for lead were found to be 13.0 and $2.91 \mathrm{mg} / \mathrm{g}$ respectively. Ash gave best fit in Freundlich isotherm with $\mathrm{r}^{2}$ value of 0.953 and adsorption capacity of $2.59 \mathrm{mg} / \mathrm{L}$. Of the three adsorbents AMC had the highest adsorption capacity which could have been due to activation. Activation increases the binding sites of the adsorbent.

Table 3: Langmuir and Freundlich constants for removal of lead

\begin{tabular}{|c|c|c|c|c|c|c|}
\hline \multicolumn{3}{|c|}{ LANGMUIR } & \multicolumn{3}{c|}{ FREUNDLICH } \\
\hline SAMPLE & $\mathbf{q}_{\max }$ & b & $\mathbf{r}^{\mathbf{2}}$ & $\mathbf{K}_{\mathbf{f}}$ & $\mathbf{1 / n}$ & $\mathbf{R}^{\mathbf{2}}$ \\
\hline AMC & 13.0 & 0.173 & 0.934 & 3.026 & 0.313 & 0.540 \\
\hline MC & 2.91 & 2.804 & 0.925 & 6.89 & 0.302 & 0.052 \\
\hline ASH & 256.4 & 8.49 & 0.001 & 2.59 & 0.902 & 0.953 \\
\hline
\end{tabular}

Table 4 shows thermodynamic adsorption constants for Langmuir and Freundlich isotherms towards cadmium (II) ions in solution. All the three adsorbents gave best fit in Freundlich isotherms with $\mathrm{r}^{2}$ values of $0.988,0,997$ and 0,997 for AMC, MC and ASH respectively.MC gave the highest adsorption capacity towards $\mathrm{Cd}^{2+}$ of 24.3 $\mathrm{mg} / \mathrm{L}$ compared to $16.06 \mathrm{mg} / \mathrm{L}$ for $\mathrm{ASH}$ and $15.61 \mathrm{mg} / \mathrm{L}$ for AMC.

Table 4: Langmuir and Freundlich constants for removal of cadmium

\begin{tabular}{|c|c|c|c|c|c|c|}
\hline \multicolumn{4}{|c|}{ LANGMUIR } & \multicolumn{3}{|c|}{ FREUNDLICH } \\
\hline SAMPLE & $\overline{\mathbf{Q}_{\max }}$ & $\mathbf{b}$ & $\mathbf{r}^{2}$ & $\overline{K_{f}}$ & $1 / \mathrm{n}$ & $\mathbf{r}^{2}$ \\
\hline AMC & 1.10 & 0.056 & 0.671 & 15.61 & 1.338 & 0.988 \\
\hline MC & 2.14 & 0.038 & 0.834 & 24.3 & 1.183 & 0.997 \\
\hline ASH & 0.807 & 0.053 & 0.247 & 16.06 & 1.159 & 0.997 \\
\hline
\end{tabular}

Table 5 shows adsorption isotherm constants for colour removal using the three adsorbents. From the table, AMC gave best fit in Langmuir model with $r^{2}=0.977$ compared to Freundlich which gave $r^{2}=0.765$. The 
maximum adsorption capacity was $12.18 \mathrm{mg} / \mathrm{l}$. for MC the data best fitted in Freundlich isotherm with $\mathrm{r}^{2}=0.965$ compared with Langmuir isotherm which gave $r^{2}=0.476$. The maximum adsorption capacity was $75.73 \mathrm{mg} / 1$. Ash gave best fit in Langmuir isotherm with $\mathrm{r}^{2}=0.992$ compared with Freundlich which had $\mathrm{r}^{2}=0.848$.

Table 5: Langmuir and Freundlich constants for colour removal

\begin{tabular}{|l|l|l|l|l|l|l|}
\hline \multicolumn{2}{|l|}{ LANGMUIR } & \multicolumn{2}{l|}{ FREUNDLICH } \\
\hline SAMPLE & $\mathbf{Q}_{\max }$ & $\mathbf{b}$ & $\mathbf{r}^{2}$ & $\mathbf{K}_{\mathbf{f}}$ & $\mathbf{1 / n}$ & $\mathbf{r}^{\mathbf{2}}$ \\
\hline AMC & 12.18 & 0.102 & 0.977 & 1.520 & 1.248 & 0.765 \\
\hline MC & 0.805 & 0.292 & 0.476 & 75.73 & 5.715 & 0.965 \\
\hline ASH & 0.301 & 0.257 & 0.992 & 378.2 & 5.680 & 0.848 \\
\hline
\end{tabular}

\section{Conclusion}

The work demonstrates that charcoal, activated charcoal and ash from maize cobs can lead to cheaper methods of water purification. Poisonous lead (II) ions and cadmium (II) ions can now be eliminated from drinking water reducing chances of poisoning. Activation increased the efficiency of the adsorbent towards $\mathrm{Pb}^{2+}$ while $\mathrm{MC}$ gave the higher adsorption capacity for $\mathrm{Cd}^{2+}$.

\section{Refrences}

[1]. UN WWAP (2006). United Nations World Water Assessment Programme.The World WaterDevelopment Report 2: Water, A Shared Responsibility. UNESCO: Paris, France.

[2]. $\quad{ }^{2}$ World Health Organization and United Nations Children's Fund.(WHO and UNICEF),(2000). Global Water Supply and Sanitation Assessment 2000 Report, WHO and UNICEF Joint Monitoring Programme for Water Supply and Sanitation.

[3]. Green, P.,Vorosmarty, C., Salisbury, J., Lammers R. (2000). Global water resources: Vulnerability from climate change and population growth.Science, $\mathbf{5 4 7 7}, 284$.

[4]. Chen, C., Dong, C., Kao, C. (2007). Distribution and accumulation of heavy metals in the sediments of Kaohsiung Harbor, Taiwan. Chemosphere, (8), 1431-1440.

[5]. Cheng, S. (2003). Heavy metal pollution in China: origin, pattern and control. Environmental Science and Pollution Research, (3), 192-198.

[6]. Chengo K., Murungi J., Mbuvi H.M. (2013) Speciation of Zinc and Copper in Open-Air Automobile Mechanic Workshop Soils in Ngara Area-Nairobi Kenya, Resources and Environment, (3), 145-154.

[7]. Chengo K., Murungi J., Mbuvi H.M. (2013) Speciation of Chromium and Nickel in Open-Air Automobile Mechanic Workshop Soils in Ngara Area-Nairobi Kenya, World Environment, (3), 143-154.

[8]. Burton, F. and Tchobanoglous, G. (1991): wastewater engineering treatment, disposal and reuse (Metcalf and Eddy, Inc,). McGrawHill, NewYork.

[9]. Ho Y.S. and McKay G. (1998). Kinetic model for Lead (II) adsorption onto Peat.Adsorpt.Sci. Technol. 16(4):243-255.

[10]. Saravanane, R. Sundararaja, T. and Sivamurthyreddy, S. (2002)."Efficiency of chemically modified low cost adsorbent for the removal of heavy metals from wastewater.A comparative study".Indian J. Env. Health.44:78-81

[11]. Mureithi, G., Onindo, O. and Muthakia, G. (2012). Kinetic and equilibrium study for the sorption of $\mathrm{Pb}$ (II) ions from aqueous phase by water hyacinth (Eichhorniacrassipes). Bulletin of the Chemical Society of Ethiopia, 2: 181-193.

[12]. Ghodbane, I.; Nouri, L.; Hamdaoui, Q.; Chiha, M. (2008)J. Harzard. Mater.152, $148-149$

[13]. Low, K.S.and Lee, C.K.(1997) Pertamka J. Sci. Technol. 5: 147-148.

[14]. Mataka LM, Salidu SM, Masamba WRL, Mwatseteza JF (2010). Cadmium sorption by Moingastenopetala and Moringaoleiferaseed powder. Int. J. Environ. Sci. Technol 3(2):131-139.

[15]. Alzaydien, A. (2009). Adsorption of methylene blue from aqueous solution onto a low-cost natural Jordanian Tripoli.American Journal of Environmental Sciences,3:197-208. 